Arq. Bras. Med. Vet. Zootec., v.65, n.2, p.547-552, 2013

\title{
Desempenho de tilápias-do-nilo alimentadas com farelo da casca de pequi
}

\author{
[Performance of Nile tilapia fed with bran made of pequi peel]
}

\author{
M.S. Pessoa, J.C.S. Avelar, A.L. Heliodoro Nascimento, K.L. Silva, A.C.M. Soares, \\ A.C.S. Camargo*, D.E. Faria Filho
}

Universidade Federal de Minas Gerais - Instituto de Ciências Agrárias - Montes Claros, MG

\section{RESUMO}

Avaliou-se o desempenho de tilápias-do-nilo alimentadas com farelo da casca de pequi (Caryocar brasiliense). Foram utilizados 200 alevinos, com idade de 37 dias e peso corporal médio de $0,63 \pm 0,25 \mathrm{~g}$, distribuídos em delineamento inteiramente ao acaso, com quatro tratamentos - zero, 20,40 e $60 \%$ de substituição de ração comercial por farelo da casca de pequi - e cinco repetições representadas por caixas de cloreto de polivinila com capacidade para 130L, contendo 10 peixes cada, totalizando 20 unidades experimentais. As características de desempenho avaliadas foram consumo de ração, peso corporal, ganho de peso, conversão alimentar, comprimento total e viabilidade criatória. A conversão alimentar $-1,96 \bar{\mu}$; $2,21 \bar{\mu} ; 2,63 \bar{\mu} ; 3,12 \bar{\mu}$ - piorou linearmente com a inclusão do farelo de casca da pequi, enquanto as demais variáveis de desempenho não foram influenciadas pelos tratamentos. Conclui-se que a inclusão do farelo da casca de pequi na ração piora a conversão alimentar, sem alterar as demais variáveis de desempenho.

Palavras-chave: Oreochromis niloticus, Caryocar brasiliense, subproduto, nutrição

\begin{abstract}
The performance of Nile tilapia fed with bran made of pequi peel was evaluated. Two hundred fingerlings, at 37 days of age and with mean body weight of $0.63 \pm 0.25 \mathrm{~g}$, were distributed in a completely randomized design with four treatments $-0,20,40$ and $60 \%$ of replacement of commercial diet with bran made of pequi peel - with five repetitions represented by boxes of polyvinyl chloride $(P V C)$ with capacity for 130 L, with 10 fish each, totalizing 20 experimental units. The performance characteristics evaluated were feed intake, body weight, weight gain, feed conversion, total length, and live viability. Feed conversion $-1.96 \bar{\mu} ; 2.21 \bar{\mu} ; 2.63 \bar{\mu} ; 3.12 \bar{\mu}$-increased linearly with the inclusion of bran made of pequi peel, while the other performance variables were not influenced by treatments. The conclusion is that the inclusion of bran peel in the pequi diet worsened feed conversion, without changing other performance variables.
\end{abstract}

Keywords: Oreochromis niloticus, Caryocar brasiliense, by-product, nutrition

\section{INTRODUÇÃO}

A alimentação na aquicultura representa normalmente mais da metade do custo de produção (El-Sayed, 1999), dessa forma é importante encontrar alimentos alternativos para diminuir os custos com a alimentação.

Recebido em 3 de setembro de 2011

Aceito em 20 de julho de 2012

*Autor para correspondência (corresponding author)

E-mail: fariafilho@ufmg.br
O pequi (Caryocar brasiliense) é um fruto advindo do pequizeiro, árvore do cerrado brasileiro, e apresenta sazonalidade que pode variar entre os meses de setembro e março. A exploração extrativista do pequi é de grande relevância para inúmeras famílias, que têm essa cultura como fonte de renda e emprego, por meio da colheita, do processamento e da comercialização do pequi (Souza e Salviano, 
2002). Após a extração do pequi, resta-lhe a casca, que representa aproximadamente $70 \%$ do peso total do fruto (Vera et al., 2007). Esse subproduto representa um problema para produtores rurais, pois é inóculo de doenças e de pragas. $\mathrm{O}$ aproveitamento deste subproduto pode representar ganhos para o produtor, melhorando a sustentabilidade da propriedade e diminuindo os custos de produção (Silva e Jesus, 2008).

O farelo da casca do pequi apresenta potencial de uso para a alimentação animal. Bonfá et al. (2009) analisaram o efeito da inclusão de zero, 10,20 e $30 \%$ do farelo da casca de pequi na dieta de caprinos e não encontraram alteração na digestibilidade aparente dos nutrientes, com exceção do extrato etéreo, o que sugere que esse subproduto apresenta viabilidade de uso, representando, assim, uma alternativa para a dieta de caprinos. Pessoa et al. (2009) avaliaram a digestibilidade dos nutrientes da casca de pequi em tilápia-do-nilo e encontraram coeficientes de digestibilidade de 97,89 e 55\% para proteína bruta, extrato etéreo e fibra bruta, respectivamente. Esses resultados mostram que o farelo da casca de pequi se apresenta como uma possível alternativa para a alimentação de peixes, no entanto são necessários testes de desempenho para avaliar a viabilidade de inclusão desse subproduto na ração.

Este trabalho teve por objetivo avaliar o efeito da utilização do farelo da casca de pequi na ração sobre o desempenho de tilápia-do-nilo.

\section{MATERIAL E MÉTODOS}

Todos os procedimentos realizados foram submetidos e aprovados pelo Comitê de Ética em Experimentação Animal da Universidade Federal de Minas Gerais, registrados sob o protocolo $\mathrm{n}^{\circ} 207 / 07$. Foram utilizados 200 alevinos de tilápia-do-nilo (Oreocrhomis niloticus), com peso inicial de $0,63 \pm 0,25 \mathrm{~g}$, revertidos sexualmente, provenientes da Companhia de Desenvolvimento dos Vales do São Francisco e do Parnaíba, Nova Porteirinha , MG. Os alevinos foram distribuídos em delineamento inteiramente ao acaso, com quatro tratamentos - $0,20,40$ e $60 \%$ de substituição de ração comercial pelo farelo da casca de pequi - e cinco repetições, com 10 alevinos cada, totalizando 20 unidades experimentais. As parcelas foram constituídas por caixas de cloreto de polivinila (PVC) com capacidade para 130 litros (410x560x780mm).

As cascas do pequi foram coletadas junto aos comerciantes (cascas desprezadas) no Mercado Central de Montes Claros e, em seguida, lavadas, cortadas em pedaços de aproximadamente $10 \mathrm{~cm}$, deixadas ao sol por um dia e secas em estufa a $55^{\circ} \mathrm{C}$, por um período de 72 horas, sendo posteriormente processadas em um moinho triturador. A composição nutricional do farelo da casca de pequi e a da ração comercial foram determinadas conforme Silva e Queiroz (2002) e estão apresentadas na Tab. 1. A composição das dietas experimentais apresentam-se na Tab. 2.

Tabela 1. Composição em matéria seca (MS), proteína bruta (PB), extrato etéreo (EE), matéria mineral $(\mathrm{MM})$, cálcio $(\mathrm{Ca})$, fósforo $(\mathrm{P})$, fibra bruta $(\mathrm{FB})$ e extrativo não nitrogenado (ENN) do farelo da casca de pequi e da ração comercial

\begin{tabular}{|c|c|c|c|c|c|c|c|c|}
\hline Alimento & $\begin{array}{c}\text { MS } \\
\%\end{array}$ & $\mathrm{~PB}$ & $\mathrm{EE}$ & $\mathrm{MM}$ & $\begin{array}{c}\mathrm{Ca} \\
\% \text { da }\end{array}$ & $\mathrm{P}$ & $\overline{F B}$ & ENN \\
\hline Farelo da & 89,68 & 4,78 & 1,08 & 3,35 & 0,31 & 0,10 & 21,81 & 68,98 \\
\hline Ração comercial & 90,91 & 42,79 & 7,07 & 15,81 & 3,94 & 1,80 & 12,23 & 22,10 \\
\hline
\end{tabular}

Tabela 2. Composição em matéria seca (MS), proteína bruta (PB), extrato etéreo (EE), matéria mineral $(\mathrm{MM})$, cálcio $(\mathrm{Ca})$, fósforo $(\mathrm{P})$, fibra bruta $(\mathrm{FB})$ e extrativo não nitrogenado $(\mathrm{ENN})$ das dietas experimentais

\begin{tabular}{lcccccccc}
\multirow{2}{*}{ Tratamento } & $\begin{array}{c}\text { MS } \\
\%\end{array}$ & PB & EE & MM & Ca & P & FB & ENN \\
\hline 0\% FCP & 90,91 & 42,79 & 7,07 & 15,81 & 3,94 & 1,80 & 12,23 & 22,10 \\
20\% FCP & 90,66 & 35,19 & 5,87 & 13,32 & 3,21 & 1,46 & 14,15 & 31,48 \\
$40 \%$ FCP & 90,42 & 27,59 & 4,67 & 10,83 & 2,49 & 1,12 & 16,06 & 40,85 \\
$60 \%$ FCP & 90,17 & 19,98 & 3,48 & 8,33 & 1,76 & 0,78 & 17,98 & 50,23 \\
\hline
\end{tabular}

FCP $=$ farelo da casca de pequi. 
A quantidade diária de ração fornecida aos peixes foi determinada como $10 \%$ do peso da biomassa de peixes, que foi determinada a cada 15 dias, por meio de biometria. A ração foi pesada com auxílio de uma balança com capacidade para $300 \mathrm{~g}$ e com divisão de $0,01 \mathrm{~g}$, foi embalada em papel-alumínio com quantidade adequada para cada parcela experimental e fornecida duas vezes ao dia, às 10 e às 15 horas.

A água utilizada no experimento provinha de um poço artesiano e uma vez por semana, durante todo o experimento, realizaram-se as análises físico-químicas de acordo com as normas do Standard Methods for Examinaton of Water and Wastewater (Clescerll et al., 2003), por meio das variáveis condutividade elétrica $(\mu \mathrm{S} / \mathrm{cm})$, oxigênio dissolvido $(\mathrm{mg} / \mathrm{L})$, potencial hidrogeniônico e temperatura $\left({ }^{\circ} \mathrm{C}\right)$. Para a mensuração dessas variáveis, foram utilizados os seguintes equipamentos: condutivímetro, oxímetro e pHmetro (MS Tecnopon Equipamentos especiais Ltda., Portátil - mPA210P). Durante o período experimental, as características $\mathrm{pH}$ e oxigênio dissolvido mantiveram-se dentro da faixa estabelecida pelo CONAMA (357/2005) e a condutividade elétrica manteve-se dentro dos níveis estabelecidos por Sipaúba-Tavares (1994). A temperatura da água manteve-se em média $3,5^{\circ} \mathrm{C}$ abaixo da temperatura mínima estabelecida como ideal $\left(28^{\circ} \mathrm{C}\right)$ por Kubitza (2000).

O desempenho foi avaliado de um a 15 , de um a 30 e de um a 45 dias, conforme Oliveira (2005), por meio do consumo de ração (CR), peso corporal, ganho de peso corporal (GP), conversão alimentar (CA $=\mathrm{CR} / \mathrm{GP})$, comprimento total e viabilidade criatória $(\mathrm{VC}=$ 100 - mortalidade).

Os dados foram tabulados e procedeu-se à análise de variância, por meio do procedimento GLM do programa SAS® (Statistical Analysis System) (SAS,1999-2001). Em caso de análise de variância significativa, o efeito dos tratamentos foi estudado por regressão polinomial considerando-se a inclusão do farelo da casca de pequi como variável independente, com auxilio do programa SAS $₫$ (Littell, 2002).

\section{RESULTADOS E DISCUSSÃO}

Os resultados de desempenho estão apresentados nas Tab. 3, 4 e 5. Não foi observado efeito significativo dos tratamentos sobre as variáveis consumo de ração, peso corporal, ganho de peso, comprimento total e viabilidade criatória.

A conversão foi influenciada significativamente pelos tratamentos nos períodos de um a 15 , um a 30 e um a 45 dias de experimento, sendo que, com o aumento da inclusão do farelo da casca de pequi, houve piora linear na conversão alimentar. Essa piora na conversão pode estar associada com a redução na quantidade de nutrientes e de energia consumidos pelos peixes, prejudicando, assim, o seu desempenho (Furuya, 2001). Resultados análogos foram descritos por Pezzato (1995) e Furuya et al. (1997), ao alimentarem peixes com alimentos de origem vegetal, com baixa densidade nutricional. $\mathrm{O}$ farelo da casca de pequi possui baixo valor proteico, pequeno teor de energia e de outros nutrientes essenciais.

Os peixes alimentados com $0 \%$ de farelo da casca de pequi foram os que apresentaram melhor conversão alimentar, sendo essa dieta a responsável por fornecer maior quantidade de nutrientes em relação às demais. Nogueira (2009), ao avaliar o desempenho e a composição bromatológica da carcaça de tilápia-do-nilo, alimentada com resíduos de hortaliças, observou que $60 \%$ de substituição de ração por resíduo de hortaliça promoveu um ótimo desempenho dos peixes. Esses resultados não são semelhantes aos obtidos no presente experimento.

De acordo com Jaramillo et al. (1996), a porcentagem de proteína na dieta deve garantir quantidades adequadas de aminoácidos para atender a uma determinada espécie, permitindo que o organismo sintetize suas próprias proteínas e, assim, assegurando sua mantença de crescimento e produção. Portanto, a concentração ótima de proteína nas dietas para peixes é determinada principalmente pelo balanceamento entre proteína e energia; além disso, é importante manter o padrão adequado de aminoácidos essenciais disponíveis e de fontes de energia não proteica, como lipídios e carboidratos (Cho, 1992). Na Tab. 6, são demonstrados os níveis de proteína recomendados para máximo crescimento de tilápias em diferentes fases de desenvolvimento. Comparando-os com as 
porcentagens de proteína apresentadas na Tab. 2, observa-se que apenas os tratamentos com $0 \%$ e $20 \%$ de FCP apresentam-se dentro da faixa recomendada para a espécie.

O grupo mais relevante de polifenóis na nutrição animal é o tanino, em razão dos efeitos deletérios no aproveitamento das rações e no desempenho produtivo dos animais (Warreham et al., 1994). Esse polifenol encontra-se presente na constituição do farelo da casca de pequi (Sousa et al., 2006). Resultados semelhantes ao deste experimento foram encontrados em pesquisas realizadas com ingredientes que continham taninos na alimentação de algumas espécies de peixes, nas quais se observaram menor digestibilidade dos nutrientes, pior taxa de conversão alimentar, baixo desempenho produtivo e menor depósito lipídico na carcaça e nas vísceras (Dy Peñaflorida, 1995; Mukhopadhyay, 1997; Fagbenro, 1999; Quintero et al., 2000).

Tabela 3. Consumo de ração (CR; g), peso corporal (PC; g), ganho de peso corporal (GP; g), conversão alimentar $(\mathrm{CA} ; \mathrm{g} / \mathrm{g})$ e comprimento total $(\mathrm{CT} ; \mathrm{cm})$ de peixes alimentados com farelo da casca de pequi (um a 15 dias)

\begin{tabular}{cccccc}
\hline Tratamento & CR & PC & GP & CA* & CT \\
\hline $0 \%$ pequi & $1,00 \pm 0,18$ & $1,43 \pm 0,28$ & $0,78 \pm 0,15$ & $1,34 \pm 0,20$ & $4,09 \pm 0,34$ \\
$20 \%$ pequi & $1,00 \pm 0,13$ & $1,24 \pm 0,19$ & $0,66 \pm 0,12$ & $1,60 \pm 0,13$ & $3,94 \pm 0,17$ \\
$40 \%$ pequi & $0,88 \pm 0,20$ & $1,11 \pm 0,23$ & $0,51 \pm 0,10$ & $1,72 \pm 0,15$ & $3,83 \pm 0,25$ \\
$60 \%$ pequi & $1,07 \pm 0,18$ & $1,17 \pm 0,19$ & $0,46 \pm 0,07$ & $2,30 \pm 0,19$ & $4,00 \pm 0,27$ \\
\hline Probabilidade & 0,9107 & 0,7568 & 0,2425 & 0,0085 & 0,9212 \\
CV $(\%)$ & 40,24 & 40,67 & 40,03 & 22,16 & 15,17 \\
\hline
\end{tabular}

Médiasterro-padrão da média. * $\mathrm{Y}=1,28959+00,01498 \mathrm{X} ; \mathrm{R}^{2}=0,91$, em que: $\mathrm{Y}=$ conversão alimentar e $\mathrm{X}=$ tratamentos.

Tabela 4. Consumo de ração (CR; g), peso corporal (PC; g), ganho de peso corporal (GP; g), conversão alimentar (CA; g/g) e comprimento total $(\mathrm{CT} ; \mathrm{cm})$ de peixes alimentados com farelo da casca de pequi (um a 30 dias)

\begin{tabular}{cccccc}
\hline Tratamento & CR & PC & GP & CA* & CT \\
\hline 0\% pequi & $3,32 \pm 0,51$ & $2,30 \pm 0,40$ & $1,64 \pm 0,27$ & $2,07 \pm 0,13$ & $5,00 \pm 0,30$ \\
$20 \%$ pequi & $2,93 \pm 0,35$ & $1,90 \pm 0,32$ & $1,32 \pm 0,26$ & $2,41 \pm 0,25$ & $4,60 \pm 0,26$ \\
$40 \%$ pequi & $2,66 \pm 0,50$ & $1,53 \pm 0,30$ & $0,94 \pm 0,15$ & $2,80 \pm 0,08$ & $4,30 \pm 0,26$ \\
$60 \%$ pequi & $2,81 \pm 0,47$ & $1,60 \pm 0,22$ & $0,90 \pm 0,11$ & $3,14 \pm 0,30$ & $4,38 \pm 0,28$ \\
\hline Probabilidade & 0,7762 & 0,3376 & 0,0744 & 0,0143 & 0,4427 \\
CV $(\%)$ & 35,44 & 38,62 & 39,45 & 18,34 & 13,61
\end{tabular}

Médias \pm erro-padrão da média. * $\mathrm{Y}=2,05796+0,018117 \mathrm{X} ; \mathrm{R}^{2}=0,99$, em que: $\mathrm{Y}=\mathrm{con} \sim \sim$ alimentar e $\mathrm{X}=$ tratamentos.

Tabela 5. Consumo de ração (CR; g), peso corporal (PC; g), ganho de peso corporal (GP; g), conversão alimentar (CA; g/g) e comprimento total $(\mathrm{CT} ; \mathrm{cm})$ e viabilidade criatória $(\mathrm{VC} ; \%)$ de peixes alimentados com farelo da casca de pequi (um a 45 dias)

\begin{tabular}{ccccccc}
\hline Tratamento & $\mathrm{CR}$ & $\mathrm{PC}$ & $\mathrm{GP}$ & $\mathrm{CA}^{*}$ & $\mathrm{CT}$ & $\mathrm{VC}$ \\
\hline $0 \%$ pequi & $6,75 \pm 1,10$ & $3,45 \pm 0,65$ & $2,80 \pm 0,52$ & $2,47 \pm 0,13$ & $5,50 \pm 0,35$ & $90,00 \pm 7,74$ \\
$20 \%$ pequi & $5,88 \pm$ & $2,97 \pm 0,55$ & $2,40 \pm 0,48$ & $2,64 \pm 0,24$ & $5,25 \pm 0,33$ & $84,00 \pm 5,10$ \\
& 0,77 & & & & & \\
$40 \%$ pequi & $4,95 \pm$ & $2,12 \pm 0,47$ & $1,53 \pm 0,34$ & $3,39 \pm 0,35$ & $4,95 \pm 0,33$ & $94,00 \pm 4,00$ \\
& 0,93 & & & & & \\
$60 \%$ pequi & $5,28 \pm$ & $2,04 \pm 0,30$ & $1,33 \pm 0,18$ & $3,94 \pm 0,14$ & $4,87 \pm 0,27$ & $96,00 \pm 4,00$ \\
& 0,75 & 0,1940 & 0,0674 & 0,0014 & 0,5246 & 0,4403 \\
\hline Probabilidade & 0,5309 & 43,22 & 45,23 & 16,97 & 14,17 & 13,34 \\
CV $(\%)$ & 35,36 & 436
\end{tabular}

Médias \pm erro-padrão da média. * $\mathrm{Y}=2,337133+0,025913 \mathrm{X} ; \mathrm{R}^{2}=0,95$, em que: $\mathrm{Y}=$ conversão alimentar e $\mathrm{X}=$ tratamentos. 
Tabela 6. Porcentagem de proteína recomendada em rações completas para máximo crescimento de tilápias em diferentes fases de desenvolvimento

\begin{tabular}{lccl}
\hline \multicolumn{1}{c}{ Espécie } & $\begin{array}{c}\text { Peso dos } \\
\text { peixes } \\
(\mathrm{g})\end{array}$ & $\begin{array}{c}\text { Proteína bruta } \\
(\%)\end{array}$ & \multicolumn{1}{c}{ Referências } \\
\hline Tilápia-do-nilo $($ O. niloticus $)$ & 1 a 10 & 40 & Siddiqui et al.,1988 \\
Tilápia-do-nilo $($ O. niloticus $)$ & 40 a 170 & 30 & Siddiqui et al.,1988 \\
Tilápia-do-nilo $($ O. niloticus $)$ & 0,4 & 30 & Furuya et al.,1996 \\
Tilápia azul $($ O. aureus $)$ & 0,4 a 10 & 36 & Davis; Stickney, 1978 \\
Tilápia-de-moçambique & pós-larvas & 50 & Jauncey, 1982 \\
Tilápia-de-moçambique & 0,5 a 1 & 40 & Jauncey, 1982 \\
Tilápia-de-moçambique & 6 a 30 & 30 a 35 & Jauncey, 1982 \\
\hline
\end{tabular}

\section{CONCLUSÕES}

A inclusão do farelo da casca de pequi na ração piora a conversão alimentar, sem alterar as demais variáveis de desempenho e as características físicas e químicas da água.

\section{AGRADECIMENTOS}

À Universidade Federal de Minas Gerais, pela disponibilização de laboratórios e técnicos para a execução das análises; aos integrantes do grupo de estudo em aquicultura - GEAQUI; ao CNPq, pela concessão da bolsa de estudo.

\section{REFERÊNCIAS}

BONFÁ, H.C.; RUFINO, L.M.A.; RIBEIRO JUNIOR, C.S. et al. Efeitos dos níveis de inclusão do farelo da casca de pequi sobre a digestibilidade aparente em caprinos. In: ZOOTEC, 19., 2009, Águas de lindoia. Anais... Águas de Lindoia, Associação Brasileira de Zootecnistas, 2009.

CLESCERLL, L.S.; GREENBERG, A.E.; EATON, A.D. Standard methods for examination of water and wastewater. Washington: EPA/APHA, 2003.

CHO, C.Y. Feeding for rainbow trout and other salmonids, with reference to current estimates of energy and protein requirement. Aquaculture, v.100, p.87-95, 1992.

DY PEÑAFLORIDA, V. Growth and survival of tiger shrimp fed diets where fish meal is partially replaced with papaya (Carica papaya) or camote (Ipoema batatas) leaf meal. Israel Aquacult., v.47, p.25-33, 1995.
EL-SAYED, A.F.M. Alternative dietary protein sources for farmed tilapia Oreochromis spp. Aquaculture, v.179, p.149-168, 1999.

FAGBENRO, O.A. Formulation and evaluation of diets for the african catfsh, Clarias gariepinus (burchell), made for partial replacement of fish meal with winged bean (Psophocarpus tetragonolobus) seed meal. Aquac. Res., v.30, p.249-257, 1999.

FURUYA, V.R.B.; HAYASHI, C.; FURUYA, W.M. Farelo de canola na alimentação da tilápia do Nilo (Oreochromis niloticus), durante o período de reversão de sexo. Rev. Bras. Zootec., v.26, p.1067-1073, 1997.

FURUYA, W.M.; PEZZATO, L.E.; PEZZATO, A.C. et al. Coeficientes de digestibilidade e valores de aminoácidos digestíveis de alguns ingredientes para tilápia do Nilo (Oreochromis niloticus). Rev. Bras. Zootec., v.30, p.1143-1149, 2001.

JAUNCEY, K. The effects of varying dietary protein level on the growth, food conversion, protein utilization and body composition of juvenile tilapias (Sarotherodon mossambicus). Aquaculture, v.27, p.43-54, 1982.

JARAMILLO, M.P.S. Nutrientes essenciales. In: JARAMILLO, M.P.S.; GÓMES, H.R.; DAZA, P.V. Fundamentos de Nutricioón y Alimentación em Acuicultura. Bogotá: Instituto Nacional de Pesca y Acuicultura, 1996. p.53-63.

KUBITZA F. Tilápia: tecnologia e planejamento na produção comercial. Jundiaí: Kubitza, 2000. 289p.

LITTELL, R.C.; STROUP, W.W.; FREUND, R.J. SAS For Linear Models. 4. ed. Cary, NC. SAS Institute, 2002. 466p. 
NOGUEIRA, W.C.L. Viabilidade técnicoeconômica da produção de Tilápia do Nilo (Oreochromis niloticus), alimentadas com resíduo de hortaliças. 2009. 58f. Dissertação (Mestrado em Ciências Agrárias) - Instituto de Ciências Agrárias, Universidade Federal de Minas Gerais, Montes Claros, MG.

MUKHOPADHYAY, N.; RAY, K. The potencial uso ofdeoiled sal (Shorea robusta) seed meal as a feedstuff in pelleted feed for Indian major carp, rohu, Labeo rohita, (Hamilton) fingerlings. Aquacult. Nutri., v.2, p.221-227, 1997.

OLIVEIRA, M.M. Caracterização química, biológica e utilização da silagem ácida de resíduos da filetagem de tilápia do Nilo (Oreochromis niloticus, L.), para alevinos de tilápia e girino de rã-touro (Rana catesbeiana Shaw, 1802). 2005. 81f. Dissertação (Mestrado em Ciência Animal) - Universidade José do Rosário Vellano, Alfenas, MG.

PESSOA, M.S.; PEREIRA, A.K.S.; VIEIRA, L.C. et al. Digestibilidade dos nutrientes da casca de pequi (caryocar brasiliensis camb.) para tilápias do nilo (oreochromis niloticus). In: ZOOTEC, 19., 2009, Águas de Lindoia. Anais... Águas de Lindoia, Associação Brasileira de Zootecnistas, 2009.

PEZZATO, L.E. Alimentos convencionais e não convencionais disponíveis para indústria da nutrição de peixes no Brasil. In: SIMPÓSIO INTERNACIONAL SOBRE NUTRIÇÃO DE PEIXES E CRUSTÁCEOS, 1995, Campos de Jordão. Anais... Campos de Jordão: Escola Superior de Agricultura "Luiz de Queiroz" Universidade de São Paulo (ESALQ).1995, p.3435 .

QUINTERO PINTO, L.G.; PEZZATO, L.E.; MIRANDA, E.C. et al. Ação do tanino na digestibilidade de dietas pela tilápia do Nilo (Oreochromis niloticus). Acta Sci., v.22, p.677681, 2000.
SAS. 1999-2001. Statistical Analyses System, User's guide: statistics. Version 8, v. 2. Cary.

SILVA, D.J.; QUEIROZ, A.C. Análise de Alimentos: Métodos químicos e biológicos. 3. ed. Viçosa:UFV, 2002. 235p.

SILVA, M.N.S.; JESUS, D.M. Territorialidades do pequi: montes claros e o norte de Minas Gerais em questão. 2008. Disponível em: <http://www.unimontes.br/coloquiointernacional / arquivos/171marcosnicolau.pdf $>$ Acessado em: 18 set. 2009

SIPAÚBA-TAVARES, L.H. Limnologia aplicada à aqüicultura. São Paulo: FUNEP. 1994. 72p.

SOUSA, W.A.; SOUSA, K.S.; MARSON, P.G. et al. Estudo fitoquímico e análise química parcial dos polissacarídeos de Caryocar brasiliense Camb. (caryocaraceae). In: REUNIÃO ANUAL DA SBPC, 58., 2006, Florianópolis. Anais... Florianópolis: [s.n] 2006. (Resumo).

SOUZA, A.I.; SALVIANO, A.A Cultura do Pequi. EMATER, 2002. Disponível em: <http://www.emater.mg.gov.br/site_emater/Serv _Prod/Livraria/Fruticultura> Acessado em: 12 fev. 2009.

VERA, R.; SOUZA, E.R.B.; FERNANDES, E.P. et al. Caracterização física e química de frutos do pequizeiro (Caryocar brasiliense camb.) oriundos de duas regiões no estado de goiás, Brasil. Pesq. Agropec. Trop., v.37, p.93-99, 2007.

WARREHAM, C.N.; WISEMAN, J.; COLE, D.J.A. Processing and antinutritive factors in feedstuffs. In: COLE, D.J.A.; VARLEY, M.A. (Eds.). Principles of pig sciences. Nottingham, 1994. 427p. 